\title{
Tarifa de energia elétrica e desenvolvimento sustentável paraense
}

\author{
Electricity and development rates sustainable paraense \\ Tarifas de electricidad y desarrollo paraense sostenible
}

Recebido: 22/01/2021 | Revisado: 24/01/2021 | Aceito: 26/01/2021 | Publicado: 01/02/2021

Fabricio Quadros Borges

ORCID: https://orcid.org/0000-0002-1326-959X Instituto Federal de Educação, Ciência e Tecnologia do Pará, Brasil E-mail: posdoctorborges@gmailk.com

\begin{abstract}
Resumo
O propósito desta investigação é examinar os elementos contribuintes às altas tarifas residenciais cobradas pela energia elétrica no estado do Pará e relacionar a contribuição destas tarifas ao processo de desenvolvimento daquele estado. Os procedimentos metodológicos se apoiaram em uma pesquisa bibliográfica e documental junto às tarifas residenciais praticadas pela eletricidade aos paraenses. O estudo constatou que os elementos tributos e encargos constituem-se como os que favorecem significativamente às altas tarifas cobradas não apenas no Pará, mas também nas demais unidades da federação do país. A investigação também indicou fatores agravantes ao valor tarifário praticado no estado paraense, como: dispersão territorial dos habitantes, dificuldade financeira da concessionária de energia elétrica paraense, erros do governo nos planos de expansão do setor de energia elétrica no estado e o consumo intensivo de eletricidade por parte de indústrias minerais. No tocante a dinâmica de desenvolvimento, verificou-se que as tarifas poderiam favorecer no momento em que pudessem proporcionar condições aos usuários de viabilizar novos negócios e melhorar a qualidade de vida, todavia, o que ocorre é uma sustentação de subsídios a organizações energointensivas e a prática de programas ineficientes junto a faixa mais baixa de renda dos usuários residenciais paraenses.
\end{abstract}

Palavras-chave: Eletricidade; Desenvolvimento; Qualidade de vida.

\begin{abstract}
The purpose of this investigation is to examine the elements contributing to the high residential tariffs charged for electricity in the state of Pará and to relate the contribution of these tariffs to the development process of that state. The methodology was based on a bibliographic and documentary survey with the residential tariffs charged by electricity to Pará. The investigation found that the factors taxes and charges are those that contribute predominantly to the high tariffs practiced not only in the state of Pará, but also in the other Brazilian states. The study also pointed out factors aggravating the tariff amount charged in Pará, such as: territorial dispersion of the population, crisis of its energy concessionaire, weaknesses in the federal planning of the electrical expansion in the state and the intensive consumption of electricity by mineral industries. As for the development process, it is emphasized that tariffs could contribute to the extent that they could provide conditions for consumers to enable new businesses and improve the quality of life, however, what occurs is a support for subsidies to energy-intensive organizations and the practice inefficient programs with the lower income bracket of residential consumers in Pará.
\end{abstract}

Keywords: Electricity; Development; Quality of life.

\section{Resumen}

El propósito de esta investigación es examinar los elementos que contribuyen a las altas tarifas residenciales cobradas por la electricidad en el estado de Pará y relacionar la contribución de estas tarifas al proceso de desarrollo de ese estado. La metodología se basó en un relevamiento bibliográfico y documental con las tarifas residenciales cobradas por electricidad a Pará. La investigación encontró que los factores impuestos y cargas son los que contribuyen predominantemente a las altas tarifas practicadas no solo en el estado de Pará, sino también en los demás estados brasileños. El estudio también señaló factores agravantes del monto de la tarifa cobrada en Pará, tales como: dispersión territorial de la población, crisis de su concesionaria energética, debilidades en la planificación federal de la expansión eléctrica en el estado y el consumo intensivo de electricidad por parte de las industrias mineras. En cuanto al proceso de desarrollo, se enfatiza que las tarifas podrían contribuir en la medida en que podrían brindar condiciones para que los consumidores habiliten nuevos negocios y mejoren la calidad de vida, sin embargo, lo que ocurre es un apoyo a los subsidios a las organizaciones intensivas en energía y la práctica. programas ineficientes con el segmento de menores ingresos de los consumidores residenciales en Pará.

Palabras clave: Electricidad; Desarrollo; Calidad de vida. 


\section{Introdução}

A energia elétrica representa uma das bases do desenvolvimento em qualquer região ou país no omento em que possui vínculos estratégico junto a sistemas de água potável, saúde, comunicações, transportes e educação. A eletricidade apoiada nas suas características físicas e químicas possibilita a operação de equipamentos através de correntes de deslocamento de cargas elétricas (Borges \& Zouain, 2010; Borges, Rodrigues \& Oliveira, 2017). O perfil de disposição da produção de energia elétrica, determinadas características de qualidade, volume e custos de garantia de uma condição competitiva estabelecem o potencial das populações em sustentar determinada condição de padrão de vida. A energia é tratada como um bem de natureza estratégica que engloba meandros socioeconômicos, político-ambientais e tecnológicos (Borges, Rodrigues \& Oliveira, 2017). A eletricidade distribuída para as moradias de populações compreende um aspecto que ganha relevância quando se aborda a missão da eletricidade para o aprimoramento da dinâmica de desenvolvimento de regiões e país. Conforme Borges, Rodrigues e Oliveira (2017), o Brasil conta notadamente com uma fonte de produção de eletricidade com reduzidos custos relativos (hidrelétricas) por um aspecto; por outro aspecto, os custos de energia elétrica no Brasil são bastante elevados em relação ao de outros países.

No contexto mundial, os custos de energia elétrica no país registravam em 2014 a $11^{\text {a }}$ colocação de mais onerosa no ranking das 28 nações que foram inseridas no estudo (Firjan, 2014). No ano de 2015, o país passou para a $5^{\text {a }}$ colocação desta pesquisa de mais cara tarifa residencial. De acordo com a Abradee (2015), a tarifa cobrada, junto as moradias, pela eletricidade no Brasil registrou US\$ 174 por mega watt-hora, ultrapassado pelo Canadá (US\$107/MWh), seguido por Coreia do Sul (US\$ 110/MWh).

O Pará, segundo maior estado do país em extensão territorial com 1.245.870,789 $\mathrm{Km}^{2}$, atrás apenas do Amazonas, constitui-se como o estado com maior capacidade de produção e exportação de energia elétrica do país (Borges, 2011). O Pará detém significativo potencial de produção de energia hídrica, o que o aponta como estratégico para o Brasil, quanto aos recursos naturais. Este potencial atribui-se a Usina hidroelétrica de Tucuruí, no Rio Tocantins (Borges, Rodrigues \& Oliveira, 2017). A capacidade de produção de eletgricidade é de 8.370 MW (Eletrobras/Eletronorte, 2015). Todavia, esta realidade energética verificada no Pará não é refletida razoavelmente em custos satisfatório pela eletricidade cobrados aos paraenses (Borges, Rodrigues \& Oliveira, 2017).

Registra-se que a tarifa praticada pela aquisição do insumo energético no estado do Pará, se mantem como uma das mais onerosas dentre as unidades da federação brasileira. Neste contexto de cobrança de tarifas junto as moradias paraenses, pode-se verificar uma contradição no setor elétrico daquele estado (Borges, Rodrigues \& Oliveira, 2017). Esta contradição se compõe no Pará, de modo possuir de um lado, a mais onerosa tarifa residencial para a eletricidade (R \$ 0,47 por kWh) fora os encargos e tributos (Aneel, 2014); e de outro lado, um estado brasileiro com capacidade exportadora deste insumo.

Várias investigações foram desenvolvidas com o emprenho de apresentar soluções para o desenvolvimento local associado a problemática dos entraves regionais para a sustentabilidade do setor elétrico, resultando em diversas propostas, seja em nível de solução local visando melhor uso dos recursos e tecnologias mais adequadas para as localidades isoladas (Muniz \& Rocha, 2013), em nível regional como a formação de redes de integração regional com outras redes e matrizes energéticas no contexto de integração dos países do Mercosul (Coelho et al., 2011), ou para o nível estadual em termos de políticas de atendimento elétrico considerando a dinâmica excludente do setor (Silva, 2005). Estudos de Borges e Zouain (2010) relatam desde os anos de 2010 que o setor elétrico do Brasil não consegue modificar a vantagem energética do Pará em tarifas de energia mais justas a população paraense. Contudo, proposta de uma estrutura de análise que parta do pressuposto de integração destas diferentes soluções com seus respectivos recursos, bem como a consideração de fatores de influência por parte da demanda para com a sustentabilidade, ainda é algo que requer estudos mais aprofundados. 
Nesta perspectiva, esta investigação indaga: Quais aspectos favorecem para que elevadas tarifas residenciais de energia elétrica posam ser cobradas a população do Pará e como estas tarifas estariam relacionadas ao processo de desenvolvimento sustentável do Pará. Assim, esta investigação propõe a análise dos elementos contribuintes às elevadas tarifas residenciais praticadas pela eletricidade no Pará e avaliar o possível vínculo da contribuição destas tarifas para a dinâmica de desenvolvimento sustentável daquele estado.

\section{Referencial Teórico}

Esta seção está dividida em duas etapas. Primeiramente trata-se a questão dos elementos contribuintes às tarifas praticadas pela aquisição de eletricidade. Em um segundo momento, aborda-se a eletricidade elétrica enquanto vetor da dinâmica de desenvolvimento sustentável.

\subsection{Elementos contribuintes às altas tarifas cobradas pela energia elétrica no Pará.}

O processo de privatização brasileiro favoreceu o surgimento de novos marcos de regulação. Nessa perspectiva no âmbito da gestão de infraestrutura no país, a regulação passou a incentivar e garantir os investimentos e favorecer a qualidade de vida dos usuários a partir de aumentos de eficiência. De acordo com Garcia (2010), a conduta de equidade no âmbito do relacionamento entre os usuários, os agentes econômicos e o Estado compreendem significativos e desafiadores aspectos da função regulatória.

Os mais relevantes propósitos da atividade regulatória são: promover motivação a investimentos e suportar eficiência na produção e na utilização (Kessler, 2011). Nas reflexões de Pires e Piccinini (1999), estes propósitos adquirem aspectos mais particulares, onde para os autores mencionados, os objetivos da regulação constituem-se em: buscar eficiência econômica de modo a garantir o serviço de reduzido custo ao usuário; impedir abusos de poder no monopólio, garantindo reduzida diferença entre preço e custo, de maneira compatível as expectativas de qualidade do referido serviço; garantir a qualidade do serviço oferecido; implantar canais de atendimento a demandas dos consumidores sobre prestação dos serviços; incentivar a inovação; garantir a padronização tecnológica e a compatibilidade entre maquinário; e, garantir proteção ambiental (Borges, Rodrigues \& Oliveira, 2017). Nesta lógica, a atividade regulatória mantém o funcionamento de limitações do governo no tocante as tomadas de decisão junto ao preço e qualidade em alguns setores de infraestrutura no Brasil (Borges, Rodrigues \& Oliveira, 2017). A intervenção do governo é justificada na medida em que, em certas situações, a concorrência não se desenvolve de maneira relativamente equilibrada, seja por que existem os monopólios naturais, ou seja por que existem externalidades neste processo (Mafra, 2010). O mercado de eletricidade compreende um monopólio natural, que apresenta, compreensivamente, reflexos financeiros e entre eles a questão tarifária da eletricidade.

A tarifa de eletricidade compreende o valor atribuído pela unidade deste insumo, o $\mathrm{kWh}$, e é composta pelos custos pertinentes desde a produção até a sua distribuição aos usuários (Abradee, 2015). De acordo com Pessanha, et al. (2010), os valores cobrados pela eletricidade traduzem o grau uso dos recursos disponibilizados, incluindo basicamente o processo de construção, disponibilidade das usinas e dificuldades na instalação das linhas de transmissão (Borges, Rodrigues \& Oliveira, 2017).

A Aneel (2015) e a Eletronorte/Eletrobras (2015) demonstram estes custos no momento em que registram que a tarifa de energia elétrica praticada junto as moradias brasileiras, é formada por custos de: geração, transmissão, distribuição, tributos e encargos (Borges, Rodrigues \& Oliveira, 2017). Os custos de produção de energia elétrica são considerados reduzidos, já que a água dos rios é que movimentas as hidrelétricas. As usinas hidrelétricas retiram energia da água corrente dos rios, por meio de turbinas, que movimentam geradores elétricos. (Borges \& Zouain, 2010; Borges, Baraúna \& Chotoe, 2015). A produção de 
eletricidade no Brasil está baseada na força dos rios e os empreendimentos hidrelétricos detém relevância no momento em que se constituem como a base do suprimento de eletricidade no país (Müller, 1995). A Aneel, neste contexto, desenvolve procedimentos de cálculo tarifário para segmentos do setor elétrico levando em conta fatores como a infraestrutura energética, e atores econômicos de incentivos à modicidade tarifária e referencial mercadológico (Manoel, et al., 2018). Os custos de transmissão de eletricidade referem-se ao transporte deste insumo, desde as usinas até as distribuidoras. Assim, insere-se neste processo as torres de transmissão, isoladores e subestações. Os custos de distribuição são pertinentes a manutenção de uma longa e segmentada estrutura formada por fios condutores, transformadores e equipamentos de medição, controle e proteção das redes de energia elétrica. (Silva, 2005; Celpa, 2011).

Conforme a Lei n 5.172 de 25 de outubro de 1966, Art. $3^{\circ}$, os tributos constituem-se como toda prestação pecuniária obrigatória, em moeda ou cujo valor nela se possa expressar, que não represente sanção de ação ilícita, estabelecida em lei e cobrada por meio de estrutura administrativa vinculada (Brasil, 1966). Os tributos que constituem a tarifa de energia elétrica notadamente, de acordo com a Aneel (2016) são: Programas de Integração Social - PIS (Lei Complementar N 7 , de 7 de setembro de 1970); Contribuição para o Financiamento da Seguridade Social - COFINS (Lei Complementar $n^{\circ} 70$, de 30 de dezembro de 1991); Imposto sobre a Circulação de Mercadorias e Serviços - ICMS (Constituição Federal 1988, Art.155º); e Custeio do Serviço de Iluminação Pública - CIP (Constituição Federal 1988, Art.149º).

Os encargos setoriais são originados por meio de legislação autorizada pelo Congresso Nacional brasileiro para viabilizar a operação das políticas governamentais para o segmento de energia elétrica, cujos valores são definidos por resoluções da Aneel (Borges, Rodrigues \& Oliveira, 2017). Em outras nações, os custos pertinentes aos encargos são patrocinados pelo poder público (Ricciardi, 2012). Os valores destes encargos estão nas resoluções da Aneel e são coletados por meio da conta de energia elétrica. Conforme a Aneel (2016), os encargos setoriais que formam a tarifa de eletricidade são: Conta de Desenvolvimento Energético - CDE (Lei no. 10.438/2002 - Alterada pela Lei no 12.783/2013); Taxa de Fiscalização de Serviços de Energia Elétrica - TFSEE (Lei n ${ }^{\circ}$. 9.427/1996 - Alterada pela Lei $\mathrm{n}^{\circ}$ 12.783/2013 - Decreto $\mathrm{n}^{\circ}$. 2.410/1997); PROINFA (Lei no 10.438/2002 - Decreto n 5.025/2004); Reserva Global de Reversão - RGR (Decreto n 41.019/1957); Compensação Financeira pela Utilização de Recursos Hídricos - CFURH (Constituição Federal de 1988); Encargos de Serviços do Sistema - ESS (Decreto n²655/1998); Operador Nacional do Sistema - ONS (Lei n 9.648/1998 -Decreto ${ }^{\circ}$ 2.335); Encargo de Energia de Reserva - EER (Lei no 10.848/2004 - Resolução Normativa no 337/2008). (Borges, Rodrigues \& Oliveira, 2017).

\subsection{Energia elétrica enquanto vetor do processo de desenvolvimento sustentável.}

A abordagem do termo desenvolvimento sustentável engloba um ambiente de múltiplos meandros. A importância de uso deste conceito, na óptica desta investigação é, notadamente, compreender o desafio da sustentabilidade diante do panorama energético que os governos enfrentam no moimento em que perseguem a consecução de uma segurança no âmbito energético e no instante em que enfrentam as questões pertinentes ao meio ambiente, que são peremptórias em termos de competitividade (Borges \& Zouain, 2010). O Relatório de Brundtland é quem define o desenvolvimento sustentável com mais detalhamento. De acordo com o relatório, de 1987, o termo é um processo de mudança no qual a direção de investimentos, a orientação do desenvolvimento tecnológico e a mudança institucional estão em harmonia e elevam o potencial corrente e futuro para reunir necessidades e aspirações humanas (Wced, 1991). O relatório apresenta uma relevante definição de crescimento, bastante discutida na pauta política internacional no que se refere às questões pertinentes à distribuição global de uso de recursos e à qualidade ambiental (Bruyn \& Drunden, 1999). Conforme Stahel (1995) e Aragón (1997), o referido documento refere-se, mesmo que veladamente, ao processo a partir de bases capitalistas de produção. Neste contexto, é que esse conceito detém 
percalços de separar-se da lógica onde o princípio essencial do desenvolvimento sustentável seria o crescimento econômico propriamente (Borges \& Zouain, 2010).

Conforme Borges e Zouain (2010), a conceituação do termo desenvolvimento sustentável também é envolvida por contradições. A problemática reside na questão onde interesses econômicos não são subjugados por bases vinculadas a ética. ética. Seu conceito supõe ainda uma nova ordem internacional, que tem como produto uma ampla redistribuição do poder (Kitamura, 1994). A lógica desta normatização de desenvolvimento, todavia, coloca em segundo plano as forças que são dominantes no mercado internacional, e os interesses dos países mais industrializados, em sustentar a condição vantajosa no contexto mundial (Redclift, 1987; Spangenberg, 2000). Os interesses dos países industrializados, na manutenção da condição de vantagem econômica no cenário mundial, representa na prática a impossibilidade de implantação deste termo, pelo menos, a partir de suas definições.

A matrix elétrica e sua disposição possui papel estratégico no processo de desenvolvimento sustentável de uma região ou país. O entendimento da matriz elétrica está vinculado ao da matriz energética. Assim, apresenta-se inicialmente uma breve definição e composição desta categoria (Borges \& Zouain, 2010). A matriz energética é a descrição de toda a geração e consumo de um país ou região discriminado quando às fontes de produção e setores de consumo para uma situação futura. Quando se descreve toda a geração e consumo de um país ou região para uma situação presente, chama-se balanço energético. A matriz energética nacional é atualmente elaborada pela Empresa de Pesquisa Energética - EPE (EPE, 2010). A matriz elétrica representa a disposição das diversas formas, especificamente, de eletricidade, disponibilizadas aos processos produtivos em determinado contexto espacial, envolvendo suas fontes de geração e utilização. A matriz elétrica pode ser utilizada na análise da produção e uso de eletricidade em determinado contexto local, de modo a permitir uma leitura a partir da conjuntura energética global (Borges \& Zouain, 2010). Esta condição permite observar que a quantidade de energia elétrica produzida deve ter sua importância associada aos tipos de fontes de geração deste insumo, assim como às formas de acesso da população. Logo, possibilita levantar subsídios de análise na tentativa de orientar ações públicas do setor elétrico que sejam mais comprometidas com o desenvolvimento sustentável (Reis, et al., 2012). Deste modo, a matriz elétrica representa um importante instrumento de análise estratégica para o desenvolvimento sustentável.

O resultado desta análise da matriz elétrica é subsídio para a tomada de decisão por parte do setor elétrico. O setor elétrico, por sua vez, constitui-se em uma organização social formada de relações sistêmicas que envolvem o processo de transformação da energia primária até a utilização final por tipo de consumidor. Estas relações são estabelecidas entre os componentes do setor elétrico, tais como: geração, transmissão e distribuição, e devem tomar como base o potencial próprio, os interesses da sociedade e as premissas do desenvolvimento sustentável (Borges \& Zouain, 2010).

\section{Metodologia}

A metodologia desta investigação é de natureza qualitativa, que conforme Pereira (2018), compreende discursos dos sujeitos, seguidos de interpretação e análises das relações de significados. Para efeitos didáticos, esta metodologia foi dividida em três tarefas: coleta de dados, tratamento de dados e análise de dados. A coleta de dados foi realizada de outubro de 2017 a fevereiro de 2018 e direcionou-se ao período entre 2005 e 2014. O procedimento de coleta de dados, limitado ao setor residencial, efetuou-se por meio de pesquisa bibliográfica e documental. No setor residencial estão as tarifas cobradas aos usuários de baixa tensão $(2,3 \mathrm{kV})$. A pesquisa bibliográfica foi pautada a partir de periódicos indexados e publicações promovidas por instituições do setor de energia elétrica no Brasil. A pesquisa documental, por seu turno, baseou-se: a cartilha por dentro da conta de luz e o caderno temático de tarifas de fornecimento de eletricidade da Aneel; relatórios da administração das Centrais Elétricas do Pará S.A. - Celpa; e relatório de acompanhamento do mercado de eletricidade da 
Eletronorte/Eletrobras. O tratamento ou tabulamento de dados desenvolveu-se em duas etapas. Na etapa inicial, construiu-se um quadro onde se verifica de modo geral a composição dos custos e a participação em percentagem destes na tarifa de eletricidade no país. Na etapa seguinte, procedeu-se uma reflexão sobre a dinâmica do desenvolvimento sustentável frente a realidade das tarifas de energia elétrica no Pará. A análise de dados, terceira e última tarefa desta metodologia, abordou inicialmente uma análise da estrutura de custos de formação da tarifa de eletricidade de modo a verificar a participação de cada elemento da formação da tarifa. Por fim, analisou-se o possível favorecimento efetivo das tarifas ao desenvolvimento sustentável no Pará.

\section{Resultados e Discussão}

A seção é constituída pela análise dos elementos e composição da tarifa de energia elétrica no Brasil e pela análise de aspectos que envolvem o processo de desenvolvimento sustentável.

\subsection{Elementos de composição da tarifa de energia elétrica.}

Esta seção será tratada em duas subseções. Inicialmente aborda-se a tarifa de eletricidade praticada nas moradias paraenses de modo associado a reflexões a luz das tarifas praticadas pela energia nas demais unidades federativas entre $2005 \mathrm{e}$ 2014. Em um segundo momento trataram-se os elementos de formação dos custos e o percentual de contribuição destes custos perante a conta de energia elétrica no Brasil.

O preço das tarifas de energia elétrica para o setor residencial das unidades da federação brasileira anotadas entre 2005 e 2014, pode ser verificado no Quadro 1.

As tarifas praticadas para a eletricidade no Pará demonstram variação significativa no período observado. No ano de 2005, o estado paraense ocupava a $16^{\circ}$ colocação, no ranking das mais onerosas tarifas de eletricidade do país, ao anotar 0,311 $\mathrm{R} \$ / \mathrm{kWh}$. Naquele momento, a mais onerosa tarifa cobrada no país foi a de ato Grosso do Sul, que registrou $0,383 \mathrm{R} \$ / \mathrm{kWh}$, seguido do Ceará $(0,364 \mathrm{R} \$ / \mathrm{kWh})$. 
Quadro 1: Tarifas de eletricidade dos estados brasileiros para o setor Residencial em:

\begin{tabular}{|c|c|c|c|c|c|c|c|c|c|c|c|}
\hline \multirow{2}{*}{ UF } & \multirow{2}{*}{ CONCESSIONÁRIAS } & \multicolumn{10}{|c|}{ ANOS } \\
\hline & & 2005 & 2006 & 2007 & 2008 & 2009 & 2010 & 2011 & 2012 & 2013 & 2014 \\
\hline $\mathrm{AC}$ & ELETROACRE & 0,306 & 0,337 & 0,308 & 0,370 & 0,349 & 0,349 & 0,417 & 0,452 & 0,428 & 0,428 \\
\hline $\mathrm{AL}$ & CEAL & 0,307 & 0,323 & 0,341 & 0,387 & 0,313 & 0,333 & 0,339 & 0,369 & 0,306 & 0,306 \\
\hline AP & CEA & 0,212 & 0,208 & 0,199 & 0,197 & 0,197 & 0,197 & 0,197 & 0,197 & 0,253 & 0,397 \\
\hline $\mathrm{AM}$ & $\mathrm{CEAM} / \mathrm{AME}^{* *}$ & 0,289 & 0,266 & 0,275 & 0,324 & 0,321 & 0,152 & 0,169 & 0,165 & 0,138 & 0,138 \\
\hline BA & COELBA & 0,342 & 0,350 & 0,369 & 0,318 & 0,326 & 0,348 & 0,382 & 0,404 & 0,293 & 0,336 \\
\hline $\mathrm{CE}$ & COELCE & 0,364 & 0,368 & 0,333 & 0,333 & 0,379 & 0,402 & 0,402 & 0,363 & 0,308 & 0,359 \\
\hline $\mathrm{DF}$ & CEB-DIS & 0,270 & 0,249 & 0,251 & 0,243 & 0,262 & 0,279 & 0,298 & 0,296 & 0,256 & 0,302 \\
\hline ES & ESCELSA & 0,305 & 0,330 & 0,289 & 0,309 & 0,329 & 0,328 & 0,338 & 0,384 & 0,298 & 0,366 \\
\hline GO & CELG-D & 0,296 & 0,312 & 0,293 & 0,293 & 0,293 & 0,293 & 0,322 & 0,361 & 0,293 & 0,350 \\
\hline MA & CEMAR-INTERLIGADO & 0,334 & 0,364 & 0,377 & 0,418 & 0,411 & 0,413 & 0,443 & 0,446 & 0,343 & 0,419 \\
\hline MT & CEMAT & 0,323 & 0,305 & 0,328 & 0,325 & 0,363 & 0,364 & 0,412 & 0,423 & 0,342 & 0,381 \\
\hline MS & ENERSUL-INTERLIGADO & 0,383 & 0,419 & 0,402 & 0,367 & 0,367 & 0,363 & 0,430 & 0,440 & 0,326 & 0,357 \\
\hline MG & CEMIG/EBO S.A/EMG** & 0,347 & 0,371 & 0,378 & 0,348 & 0,367 & 0,357 & 0,379 & 0,390 & 0,331 & 0,359 \\
\hline PA & CELPA & 0,311 & 0,308 & 0,267 & 0,319 & 0,330 & 0,369 & 0,369 & 0,395 & 0,357 & 0,479 \\
\hline PB & EPB & 0,330 & 0,351 & 0,350 & 0,394 & 0,335 & 0,348 & 0,375 & 0,387 & 0,304 & 0,367 \\
\hline PR & COCEL/COPEL-DIS** & 0,313 & 0,294 & 0,305 & 0,275 & 0,305 & 0,316 & 0,320 & 0,314 & 0,250 & 0,336 \\
\hline $\mathrm{PE}$ & CELPE & 0,320 & 0,335 & 0,338 & 0,347 & 0,323 & 0,319 & 0,344 & 0,361 & 0,298 & 0,350 \\
\hline PI & CEPISA & 0,320 & 0,320 & 0,361 & 0,387 & 0,364 & 0,373 & 0,419 & 0,442 & 0,406 & 0,406 \\
\hline $\mathrm{RJ}$ & AMPLA/ENF/LIGHT** & 0,363 & 0,353 & 0,319 & 0,345 & 0,344 & 0,341 & 0,363 & 0,382 & 0,321 & 0,391 \\
\hline $\mathrm{RN}$ & COSERN & 0,279 & 0,273 & 0,288 & 0,281 & 0,298 & 0,351 & 0,389 & 0,413 & 0,391 & 0,391 \\
\hline RS & AESSUL/HIDROPAN/ELETROCAR ${ }^{* *}$ & 0,288 & 0,291 & 0,314 & 0,334 & 0,341 & 0,268 & 0,304 & 0,317 & 0,247 & 0,247 \\
\hline RO & CERON & 0,329 & 0,355 & 0,350 & 0,397 & 0,318 & 0,351 & 0,389 & 0,413 & 0,391 & 0,391 \\
\hline RR & BOA VISTA ENERGIA & 0,275 & 0,301 & 0,303 & 0,355 & 0,263 & 0,268 & 0,304 & 0,317 & 0,247 & 0,247 \\
\hline $\mathrm{SC}$ & CELESC-DIS/COPERALIANÇA & 0,324 & 0,324 & 0,340 & 0,327 & 0,314 & 0,341 & 0,351 & 0,347 & 0,318 & 0,399 \\
\hline SP & BAND $/$ ELEKTRO/CPFL/ELET.** & 0,334 & 0,344 & 0,3387 & 0,323 & 0,332 & 0,342 & 0,378 & 0,383 & 0,329 & 0,348 \\
\hline SE & ESE/SULGIPE & 0,334 & 0,344 & 0,3387 & 0,323 & 0,332 & 0,342 & 0,378 & 0,383 & 0,329 & 0,348 \\
\hline TO & CELTINS & 0,364 & 0,403 & 0,4285 & 0,410 & 0,386 & 0,418 & 0,447 & 0,420 & 0,378 & 0,420 \\
\hline
\end{tabular}

(*) As tarifas são expressas na unidade em R $\$$ / kWh e não contemplam tributos e ICMS, contribuição, PIS e CONFINS. (**) Foram realizadas médias das tarifas dos Estados que possuem mais de uma concessionária de energia elétrica. Fonte: Elaborado pelo autor (2020) a partir de Aneel (2015).

O preço das tarifas praticadas aos paraenses, a partir de 2008, registrou variação crescente e constante, de modo a anotar no ano de 2014 a $1^{\circ}$ colocação na relação das tarifas de energia elétrica mais onerosas do país (R\$ 0,479/kWh). O principal registro fora da curva deste aumento constante entre 2008 e 2014 ocorreram em 2011, onde a tarifa permaneceu constante em relação ao ano anterior e 2013. O crescimento do valor das tarifas cobradas no estado paraense no período entre 2005 e 2014 se atribuiu aos reajustes implantados pela agência de regulação de eletricidade. Neste espaço temporal, a concessionária solicitou à agência, reajustes de tarifa e o ajuste da receita da concessionária. As razões estão no crescimento dos encargos setoriais, aos quais cita-se o aumento da Conta de Consumo de Combustíveis - CCC e da Conta de Desenvolvimento energético - CDE. 
Em 2007 registrou-se um destaque na lógica do reajuste de tarifas, já que o crescimento tarifário foi de 13,06\% consequência da segunda revisão tarifária desde a primeira ocorrida em 2003, contrariamente a 2006, que foi de 1,74\% (Aneel, 2015). O referido reajuste originou o aumento constante das tarifas cobradas aos paraenses. O reajuste aconteceu em decorrência da Celpa precisar adquirir uma maior quantidade de eletricidade para suprir a demanda no espaço temporal programado, que foi de julho de 2007 a julho de 2008. Em 2008, o que se verificou foi uma elevação gradual, nesta oportunidade por meio de uma elevação de 19,4\% de 2007 para 2008. Simultaneamente a este contexto tarifário, o Pará chama a atenção por suas características de estado exportador de eletricidade. Nesta avaliação aponta-se que já em 2009, as tarifas praticadas pela energia elétrica no Pará $(\mathrm{R} \$ 0,330 / \mathrm{kWh})$ eram mais elevadas que dois dos estados que importam este insumo dos paraenses (Amazonas R\$0,321/kWh e Goiás R\$0,293/kWh).

No tocantes aos custos de formação da tarifa de energia elétrica e o percentual da participação destes custos na conta de eletricidade brasileira, a investigação destaca uma severa quantidade de tributos e encargos embutidos nas tarifas de energia elétrica cobradas em todas as unidades da federação; em outras nações, os custos referentes aos encargos são pagos pelo poder público (Ricciardi, 2012). O exame dos custos de formação da tarifa de eletricidade cobradas no país pode ser viabilizado por meio do Quadro 2.

Quadro 2. Custos que compõem a tarifa de eletricidade no Brasil (2015).

\begin{tabular}{|c|c|c|}
\hline CUSTOS & COMPOSIÇÃO DOS CUSTOS & $\begin{array}{l}\text { PARTICIPAÇÃO DOS } \\
\text { CUSTOS NA CONTA DE } \\
\text { ELETRICIDADE }(\%)\end{array}$ \\
\hline GERAÇÃO & $\begin{array}{l}\text { - } \text { Projeto de construção da Usina } \\
\text { - Execução de obras civis } \\
\text { - } \text { Aquisição de equipamentos } \\
\text { - Instalação da infraestrutura } \\
\text { - Operações de viabilidade do projeto } \\
\text { - } \quad \text { Custos financeiros }\end{array}$ & 31,0 \\
\hline TRANSMISSÃO & $\begin{array}{l}\text { - Uso das instalações de transmissão classificadas } \\
\text { como rede básica } \\
\text { - Uso das instalações de distribuição } \\
\text { - Conexão às redes de distribuição } \\
\text { - Transporte da energia proveniente das Usinas até o } \\
\text { ponto de conexão à Rede Básica } \\
\text { - Uso do sistema de transmissão pelas centrais } \\
\text { geradoras }\end{array}$ & 5,70 \\
\hline DISTRIBUIÇÃO & - Serviços prestados pela distribuidora & 26,50 \\
\hline \multirow[t]{2}{*}{ TRIBUTOS } & $\begin{array}{l}\text { - } \text { Contribuição para Custeio do Serviço de } \\
\text { Iluminação Pública - CIP } \\
\text { - } \text { Imposto sobre a Circulação de Mercadorias e } \\
\text { Serviços - ICMS } \\
\text { - } \text { Programa de Integração Social - PIS } \\
\text { - Contribuição para o Financiamento da Seguridade } \\
\text { Social - COFINS }\end{array}$ & 25,90 \\
\hline & $\begin{array}{l}\text { - Conta de Desenvolvimento Energético - CDE } \\
\text { - Taxa de Fiscalização de Custear o funcionamento } \\
\text { da Aneel Serviços de Energia Elétrica - TFSEE }\end{array}$ & \\
\hline
\end{tabular}




\begin{tabular}{|c|c|c|}
\hline ENCARGOS & 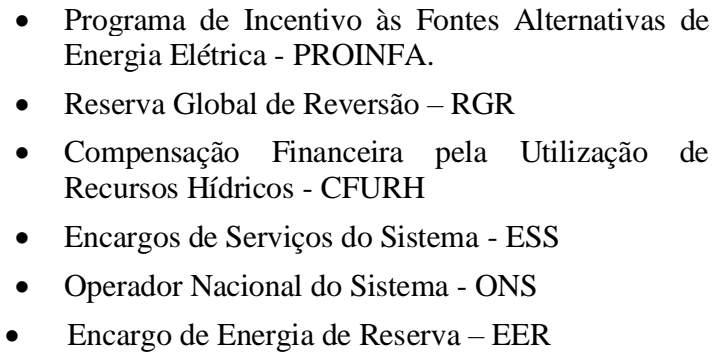 & 10,90 \\
\hline
\end{tabular}

Fonte: Autores (2020) baseado em Aneel (2015) e Eletrobras/Eletronorte (2015).

Observa-se que 36,8\% da tarifa praticada para a energia elétrica no país são pertinentes a encargos e tributos. Esta realidade deixa o país com maior percentagem de tributação em relação nações como a Holanda e o Reino Unido (Abradee, 2015).

\subsection{Aspectos que envolvem o processo de desenvolvimento sustentável.}

Os avanços no processo de desenvolvimento paraense a partir dos investimentos em energia elétrica desde a década de 80 são inquestionáveis. O Pará apresentou uma modificação em suas características econômicas que compreende o resultado de uma política energética que tem fornecido relativo suporte à modernização do perfil tecnológico nos arranjos produtivos e na dinamização de cadeias produtivas locais. O processo de modernização da Administração Pública e o fortalecimento global de investimentos de infraestrutura contribuíram para estes avanços. Entretanto, este estudo concluiu que a tendência de crescimento dos investimentos em energia elétrica e o aumento constante do consumo deste insumo em todos os setores de atividade no Pará não estão se traduzindo estrategicamente em desenvolvimento socioeconômico e em uma melhoria concreta das condições de vida dos paraenses de forma sustentável e de modo compatível com o grande potencial energético do Estado.

A ideia defendida é a de que a energia elétrica é gerada no Estado do Pará em função de elites e do interesse nacional representado por regiões mais desenvolvidas economicamente. A melhoria do perfil socioeconômico do estado, verificado nos últimos dez anos, representa apenas uma pequena fatia das possibilidades que poderiam ter sido desenhadas junto a realidade local, enquanto os impactos ambientais representam o legado de uma energia elétrica gerada localmente e que não se utiliza, em maior parte, no estado. Esta dinâmica, através de um processo dialético, faz com que o favorecimento dessas elites, na figura de grandes grupos econômicos implique, necessária e contraditoriamente, no fortalecimento dos vários grupos atingidos pelos impactos dessa geração através de um amplo processo de exclusão social.

O estado paraense permanece somente a disponibilizar insumo energético a regiões centrais do país, que são dotadas de economias mais estruturadas e competitivas. A Eletronorte mantém as hidrelétricas na medida em que acreditam que o potencial hídrico que o país dispõe deve ser explorado em atendimento às novas demandas. Neste sentido, o Pará, ao deter uma restrita capacidade de consumo serve somente como base geradora de insumos baratos à sustentação desta condição de exclusão. Este cenário, além de direcionar aos paraenses significativos impactos socioambientais decorrentes do processo de implantação desses grandes projetos posiciona o Pará em uma condição de submissão à lógica do capital no momento em que afasta as suas comunidades de benefícios vinculados ao acesso à energia elétrica em condições justas, em favor da ampliação imediata do PIB brasileiro em curto prazo.

As chances de contribuição para a modificação deste quadro residiram, inicialmente, na identificação do papel do setor elétrico na dinâmica do desenvolvimento socioeconômico do Pará através dos setores de atividade. Este esforço foi alicerçado em uma concepção cuja experiência adquirida com o passado, alimentadas por observações presentes criou condições de melhor orientar o planejamento público. Todavia, como destacaram Reis, Fadigas \& Carvalho (2012), a coleta de ensinamentos e diretrizes nem sempre compreende uma tarefa de simples consulta ao passado apenas para colher críticas ao 
presente, desprezando as incertezas e as armadilhas do tempo, sem maiores compromissos com a construção do futuro. $\mathrm{O}$ universo das reflexões deve ser baseado na percepção de que o futuro é alicerçado por ações verificadas a cada momento, mas sua realização estará sujeita as forças variadas que estão além do alcance dos estudiosos.

\section{Conclusão}

Este estudo a respeito do panorama energético do estado do Pará demonstra uma situação onde uma unidade da federação brasileira ao mesmo tempo em que detém uma característica exportadora de energia elétrica para outras unidades federativas, é detentora da mais alta tarifa residencial de energia elétrica do Brasil.

Nesta perspectiva, a investigação questionou a respeito de quais os componentes que são responsáveis pelas altas tarifas de energia elétrica praticadas aos usuários do estado e quais as conexões entre esta tarifa e o processo de desenvolvimento sustentável naquele estado brasileiro. Verificou-se neste estudo que os tributos e encargos representam os fatores que favorecem notadamente às altas tarifas cobradas não somente no estado do Pará, mas também nos outros estados do país. As tarifas cobradas pela eletricidade no estado do Pará estão incluídas em uma política nacional que embute na tarifa de eletricidade dos usuários do país tributos e encargos com o objetivo de financiar o crescimento da infraestrutura brasileira e isto é contribuitivo aos altos valores da eletricidade no país. O estudo constatou que elementos agravantes também favorecem para que a tarifa residencial de eletricidade cobrada Pará aumentasse significativamente nos anos de 2000 e de 2010. Citam-se estes elementos a seguir: a dispersão da população paraense em seu território, a crise financeira da concessionária de eletricidade do Pará, os erros nos planos de desenvolvimento do setor de energia elétrica no estado, e o padrão de consumo intensivo de eletricidade pelas organizações de extração de minérios no estado paraense.

Quanto ao processo de desenvolvimento, destaca-se que as tarifas poderiam contribuir na medida em que pudessem proporcionar condições aos consumidores de viabilizar novos negócios e melhorar a qualidade de vida; todavia, o que ocorre é uma sustentação de subsídios a organizações energointensivas e a prática de programas ineficientes junto a faixa mais baixa de renda dos consumidores residenciais no Pará. Assim, o estado do Pará continua servindo ao país apenas como fonte de insumos a baixo custo, o que impõe a sua população uma condição excludente articulada pelo capital. As características dos grandes projetos hidroelétricos não têm favorecido estrategicamente o desenvolvimento sustentável do Pará.

No tocante a trabalhos futuros de investigação, aponta-se para estudos direcionados a internalização nas tarifas de energia elétrica das externalidades decorrentes dos impactos socioambientais da implantação de hidrelétricas, que por sua vez, revelam acirradas reflexões quanto as limitações e potencialidades desta fonte de geração de eletricidade no âmbito do desenvolvimento sustentável no Pará.

\section{Referências}

Associação Brasileira de Distribuidores de Energia Elétrica (ABRADEE). (2015). Coletiva de Imprensa destinada para a apresentação comparativa Internacional de Tarifas de Eletricidade. http://www.abradee.com.br/imprensa/artigos-e-releases/2498-release-e-apresentacao-coletiva-de-imprensa-paradivulgacao-comparacao-internacional-de-tarifas-de-energia-eletrica-abradee-edicao-2015.

Agência Nacional de Águas (ANA). (2012) Conjuntura de recursos hídricos no Brasil. http://www2.ana.gov.br/Paginas/default.aspx.

Agência Nacional de Energia Elétrica (ANEEL). (2015). Tarifas da classe de consumo residencial de uma concessionária. http://www.aneel.gov.br/area.cfm?idArea=493.

Agência Nacional de Energia Elétrica (ANEEL). (2016). Por dentro da conta de energia: Informação de utilidade pública. http://www.aneel.gov.br/arquivos/PDF/Cartilha_Por_Dentro_da_Conta_de_Energia\%282011\%29.pdf.

Borges, F. Q.; Baraúna, N. C.; Chotoe, J. (2015). Fontes renováveis de energia elétrica e qualidade de vida em comunidades na Ilha do Marajó, Pará. Revista Desenvolv. Meio Ambiente. Vol. 33, abril. p. 225-239 DOI: http://dx.doi.org/10.5380/dma.v33i0.35447

Borges, F. Q. (2011). Uma análise sustentável da energia elétrica nos domicílios paraenses. Revista de Ciências Ambientais, 5(1), 69-88. https://revistas.unilasalle.edu.br/index.php/Rbca/article/view/138 
Borges, F. Q. \& Zouain, D. M. (2010). A matriz elétrica no estado do Pará e seu posicionamento na promoção do desenvolvimento sustentável. Planejamento e Políticas Públicas, 2(35), 187-221. file://C:/Users/docto/Downloads/201-589-1-PB\%20(4).pdf

Borges, F. Q.; Rodrigues, I. M.; Oliveira, A. S. P. (2017). Paradoxo da energia elétrica no estado do Pará: um estudo dos fatores que contribuem às altas tarifas residenciais (2005-2014), Revista Observatorio de la Economía Latino-americana, Espanha. 23-39. https://www.eumed.net/cursecon/ecolat/br/17/energiaelectrica-para.html

Bonini, M. R. (2011). Tarifas de Energia Elétrica: evolução nos últimos anos e perspectivas. Boletim de economia. v.8, outubro.

Brasil. (1966). Lei 5.172, de 25 de outubro de 1966. Dispõe sobre o Sistema Tributário Nacional e institui normas gerais de direito tributário aplicáveis à União, Estados e Municípios. Código Tributário. Diário Oficial da União, Brasília, 27 out.

Cardoso, B. F.; Oliveira, T. J. A. de \& Silva, M. A. da R. (2013). Eletrificação Rural e desenvolvimento local uma análise do Programa Luz Para Todos. Revista Desenvolvimento em Questão. 11(22), 117-138.

Centrais Elétricas do Pará (CELPA). (2011). Relatórios de administração. Exercícios 2003 a 2010. Celpa.

Centrais Elétricas do Norte do Brasil S.A (ELETRONORTE)/Centrais Elétricas Brasileiras S.A. (ELETROBRAS). (2013). Informativo de produção de eletricidade. http://www.brasil.gov.br/infraestrutura/2013/04/consumidores-serao-informados-sobre-custo-de-geracao-de-energia.

Centrais Elétricas do Norte do Brasil S.A (ELETRONORTE). (2004). Relatório de acompanhamento do mercado de energia elétrica. Dezembro 2003. Brasília.

Coelho, M.; Miranda, E.; Wanderley, L. \& Garcia, T. (2011). Questão energética na Amazônia: disputa em torno de um novo padrão de desenvolvimento econômico e social. Novos Cadernos NAEA, 13(2).

Empresa de Pesquisa Energética (EPE). (2016). Consumo nacional de energia http://www.epe.gov.br/mercado/Paginas/Consumonacionaldeenergiael\%C3\%A9tricaporclasse\%E2\%80\%931995-2009.aspx.

Eurostat Information. (2016). Electricity price statistics. Main tables and Database. http://ec.europa.eu/eurostat/statisticsexplained/index.php/Electricity_price_statistics\#Further_Eurostat_information.

Federação das Indústrias do Estado do Rio de Janeiro (FIRJAN). (2014). Nota técnica. Perspectivas do custo da energia elétrica para a indústria no Brasil em 2014 e 2015. $\mathrm{n}^{\circ} .1$, maio.

García H., C. L. (2010). Modelo regulatório do setor elétrico no Brasil e sua repercussão jurídica nos contratos de concessão de transmissão de energia elétrica. Programa de Engenharia Elétrica. Universidade de São Paulo-USP (Dissertação de Mestrado).

Instituto de Brasileiro de Geografia e Estatística (IBGE). (2010). Censo demográfico. http://censo2010.ibge.gov.br/.

Kessler, D. P. (2011). Regulation versus litigation: perspectives from economics. London: National Bureau of economic Research.

Mafra, D. D. (2010). Análise da composição tarifária de energia elétrica em Santa Catarina. Florianópolis: Universidade Federal de Santa CatarinaUFSC/Centro Socioeconômico, (Monografia).

Manoel, C. A. S.; Hayashi, C. \& Silva, L. H. de A. e. (2018). A importância da Aneel na prestação dos serviços de energia elétrica no Brasil. Research, Society and Development, 7(7), 1-17.

Müller, A. (1995). Hidrelétricas, meio ambiente e desenvolvimento. Makron Books.

Muniz, R. N. \& Rocha, B. R. P. D. (2013). Gaseificação de Biomassa Residuária na Amazônia: Estudo de Caso em Comunidade Quilombola no Pará. Anais do Congresso Internacional de Bioenergia, 8, São Paulo: USP.

Pereira A. S. et al. (2018). Metodologia da pesquisa científica. Ed. UAB/NTE/UFSM. https://repositorio.ufsm.br/bitstream/handle/1/1 5824/Lic_Computacao_Metodologia-Pesquisa-Cientifica.pdf?sequence=1.

Pessanha, J. F. M., Mello, M. A. R. F. de, Barros, M. \& Souza, R. C. (2010). Avaliação dos custos operacionais eficientes das empresas de transmissão do setor elétrico Brasileiro: uma proposta de adaptação do modelo DEA adotado pela Aneel. Pesquisa Operacional. 30(3) 521-545.

Pinto, L. F. (2012). O maior contrato de energia do Brasil. https://valeqvale.wordpress.com/2012/09/27/o-maior-contrato-de-energia-do-brasil/.

Pires, J. C. L. \& Piccinini, M. (1999). A regulação dos setores de infraestrutura no Brasil. In: Giambiagi, F. \& Moreira, M. (Orgs.) A economia brasileira nos anos 90 . Rio de Janeiro, BNDES.

Reis, L. B., Fadigas, E. A. A., \& Carvalho, C. E. (2012) Energia, recursos naturais e a prática do desenvolvimento sustentável. Barueri-SP: Manole.

Ricciardi, A. (2012). O enigma do alto preço da energia. (80a ed.). http://www.osetoreletrico.com.br/web/component/content/article/57-artigos-ematerias/928-o-enigma-do-alto-preco-da-energia.html.

Silva, M. V. M. da. (2005). A dinâmica excludente do sistema elétrico paraense. Programa de Interunidades em Energia- EP/FEA/IEE/IF-USP, São Paulo. (Tese de Doutorado) - USP. 